\title{
TO CATCH A WAVE
}

\section{Ocean wave energy is trying to break into the renewable-energy market, but many challenges remain. Ewen Callaway reports.}

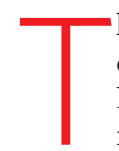
he North Sea is not known for calm days, and neither is its inlet called Nissum Bredning, 300 kilometres northwest of Copenhagen. On a typical afternoon, windsurfers skate across the grey-green water while birds seem to hover, frozen, in mid-air. Along the horizon stretch rows of giant white windmills, their long blades whirring in the gusts.

"There's really some good action today," Per Steenstrup shouts over the gust as a mix of sea water and rain pelts his face. Steenstrup, an engineer from Copenhagen, is 200 metres offshore, aboard a steel platform with 20 large floats on each side lined up like oars on a Viking ship. A knee-high wave washes under the platform, and the floats move up and down a dozen centimetres in quick succession.

Steenstrup opens the door to a small prefabricated structure on the platform, and suddenly a mechanical roar rises above the noise of the wind and sea. "It's a 40-piston engine running on waves," he yells. In the control room next door to the turbine, Steenstrup peers at a computer that keeps an instantaneous pulse on the Wavestar, as the platform is called. "At the moment, the output of power is around 800 watts," he says - enough to run a large-screen plasma television.

The wind turbines on the horizon, for their part, are components in a wellestablished system that produces 41 megawatts of wind power. That's enough on some days to power the entire agriculturedense region.

Yet Steenstrup and dozens like him think that power harvested from ocean waves will one day be competitive with other methods for extracting energy from the physical environment such as wind, solar and hydroelectric. Wave energy is applicable only in a few regions of the world, and uses technologies that, for the most part, remain unproven. But given the scale of the energy challenge facing the world, supporters say that wave energy could supply enough electricity to make it part of a green-energy portfolio.
The European Ocean Energy Association in Brussels, for instance, estimates that the global resource for wave energy lies between 1 and 10 terawatts; the world currently produces about 13 terawatts from all sources. Others see a more realistic number of 0.2 terawatts, or less, coming from wave energy; that's still three times the current installed capacity for wind power worldwide.

Whether wave energy becomes economical depends heavily on a new round of open-ocean tests that are under way from Portugal to Wales to Oregon. Engineers and entrepreneurs are field-testing machines that until now have been scale models in water tanks. Few are looking for profits; they just want to see if the technologies can produce a consistent amount of power from the ocean. Success could attract funds from investors, industry and utilities; failure could set the field back years.

"A lot is riding on how well the first sets of large-scale devices work," says Tom Thorpe of the consultancy firm Oxford Oceanics in Grove, UK, which advises prospective waveenergy investors and developers. “They've got to be either successful or, if they fail, there has to be a good reason why."

\section{Blowing in the wind}

Wave energy's most obvious parallel - and, perhaps, competitor - is wind energy. "We are where wind was 25 years ago," says Alla Weinstein, director of ocean energy at Finavera Renewables in Vancouver, Canada. Finavera's prototype, the Aqua Buoy, sank off the coast of Oregon last month after operating for two months and before it was scheduled to be taken out of the water later this month. A quarter of a century ago, world capacity for wind energy was around 90 megawatts. But that was a ninefold jump from just two years previously, and today countries such as Denmark and Germany get more than a tenth of their power from wind - although it still accounts for just $1 \%$ of energy produced worldwide.

Global figures for the power that waves produce are hard to pin down, as most projects are still in the testing phase. But when the industry's leading company, Pelamis in Edinburgh, Scotland, gets a new project online in Portugal - as is expected within weeks - that will add 
THE POWER OF WAVES

Engineers have developed at least six main types of machine to harvest the mechanical power of waves. Field tests currently under way should reveal which of these will ultimately be practical.

崖 2.25 megawatts from three machines. And wave-energy proponents think that the growth could be exponential after that.

Waves offer several improvements over wind, although they are trickier to harvest. Wind is notoriously fickle; when gusts fail, utility companies have to deliver power to their customers from other sources. Waves can be fickle too, but are easier to predict, says George Hagerman, an engineer at Virginia Tech's Advanced Research Institute in Arlington, who forecasts wave-energy days in advance using weather satellites. Knowing when waves are coming and how big they will be can save utilities money by cutting down on the power they need to keep ready in reserve, he says.

Water is not only more reliable than wind; it is also 800 times the density of air. Aboard the Wavestar, it's not a hard concept to grasp. "This is a big guy," Steenstrup says, eyeing an approaching metre-high curl like a surfer would. It hits head-on, and sea foam gushes over the floats. The steel platform shudders, even though it's anchored to the seabed by concrete piles.

Like other renewable energies, wave power works better in some locations than others. It takes more than just a shore to harness the power of waves. Because of the planet's prevailing winds, the best spots are on the west coast of continents in the mid-latitudes of the Northern Hemisphere, or on the east coast in the Southern Hemisphere. Not coincidentally, most waveenergy tests are being installed in those spots in the North Atlantic and North Pacific oceans.

Some of the strongest waves hit the Orkney Islands in Scotland, where the European Marine Energy Centre has established a wave-energy test site two kilometres offshore. The centre, which receives both government money and private funding, offers developers steady waves and easy connection to electricity grids to fieldtest machines. Pelamis began testing a 750-kilowatt wave machine there in 2004, although it is now gone. Four other manufacturers plan to join the site in the next two years. In the Southern Hemisphere, Australia-based Oceanlinx has been testing a 600-kilowatt machine off Port Kembla, New South Wales, since 2005, and is working on a larger, 2-megawatt model.

In such places, wave energy could provide an alternative source of renewable energy to the usual standbys of wind and solar. Given recent government mandates to increase the power generated from renewable-energy sources - the European Union is aiming for $20 \%$ from renewables, and California 33\%, by 2020 - wave power could be another much-needed option. The targets are aggressive enough that all options could be needed, says Dan Kammen, director of a renewable-energy laboratory at the University of California, Berkeley.

\section{Attenuator}

This floating device effectively 'rides' the waves, flexing as they pass.

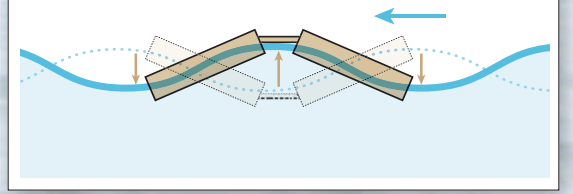

This float absorbs wave energy from all directions as it bobs up and down.

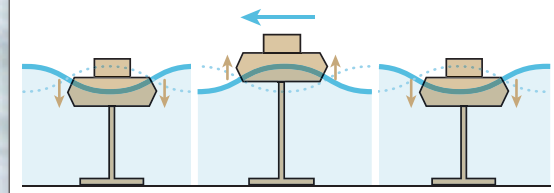

Oscillating wave surge converter

The tethered arm acts as a pendulum in response to wave surges.

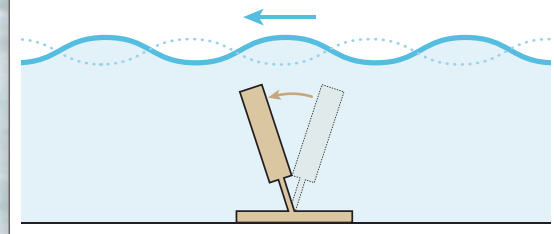

\section{Oscillating water column}

As the water level goes up and down, a column of air is compressed and decompressed, powering a turbine.

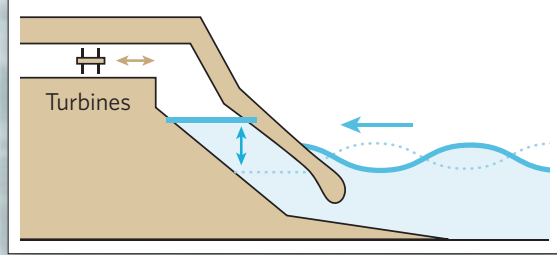

\section{Overtopping device}

Collecting water from waves in a reservoir, this device powers a turbine as the captured water drains away.

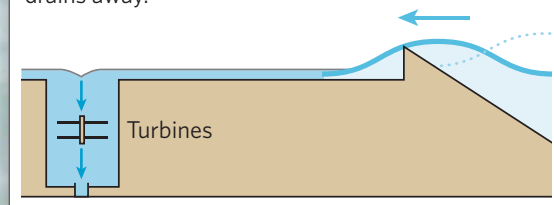

\section{Submerged pressure differential}

As this device responds to the waves, a pressure differential is set up inside it, which is used to pump fluid and so generate electricity.

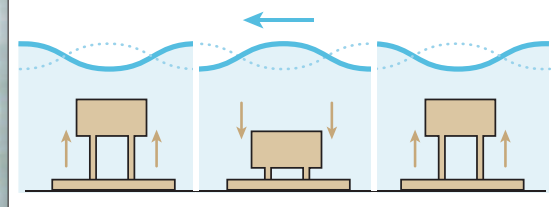

\section{Point absorber}

Some energy companies and industrial giants are already starting to take notice. At a September conference in Porto, Portugal, representatives from the national utilities of France, Denmark and Portugal attended the usually science-focused meeting. In California, the utility behemoth Pacific Gas and Electric has sought permission to establish wave-energy test sites off the coast of northern California. And in 2005, the hydroelectric firm Voith Siemens in Heidenheim, Germany, purchased Wavegen, a Scottish developer.

\section{Patents and promises}

For much of its 200-year history, wave energy has been flush with ideas but short on results. In 1799, French engineer Pierre Girard and his son filed the first patent to harness power from waves. Never constructed, the device was to work by linking the bobbing of moored ships to heavy machinery ashore via a plank and fulcrum. Through the nineteenth and twentieth centuries, patents trickled out of inventors' workshops, but no machine ever produced enough power to gain widespread use.

Wave energy's supporters began moving out of garages and into government ministries in the early 1970s. The embargo imposed by the Organization of the Petroleum Exporting Countries (OPEC) propelled the price of crude oil from $\$ 7$ in 1970 to $\$ 38$ by 1974 . Many countries saw independence from Middle East oil in renewables, beefing up their research into wind and solar energy. When it came to ways to get energy from the sea, the United States mounted an ultimately unsuccessful effort to capture thermal energy from oceans by exploiting the temperature difference between deep and surface water (see 'Energy from the sea', overleaf). Meanwhile, Britain led the way in wave energy.

In 1974, the UK government commissioned academia and industry to draw up plans for how the country could bring wave power into the mainstream. The first prototypes for wave-energy machines were "hopelessly uneconomic", says Thorpe. The plans called for massive machines that cost more than $\$ 100$ million each to generate 2,000 megawatts of electricity - roughly the output of the nuclear and oilpowered plants they were designed to replace. No rationales were given as to how such a technological leap would be made, says Thorpe. None of the proposed plants was ever built.

A 1983 progress report effectively ended Britain's foray into wave energy, saying that the technology was unproven and too costly. Developers felt betrayed by the criticism, prompting the government to commission Thorpe to repeat the review; yet he came to a similarly dim conclusion in 1992.

As wind energy took off in the 1980s, wave 
energy went back to its roots, in university laboratories and inventors' workshops. Lessons learned from the early failures and from offshore oil rigs would guide the designs of a new generation of machines.

Currently, at least 50 wave-energy projects are in development, with more appearing every year. Analysts divide the machines into more than half a dozen breeds (see graphic), each with a different trick to turn waves into electricity. Pelamis' resembles a giant snake with three segments that shimmy back and forth. Oceanlinx's looks like a giant steel bagpipe that's played by a rising and falling water column. And Finavera's are oversized buoys that use waves to drive hydraulic pumps.

Such heterogeneity is natural for a field in its early days - but within a decade the various designs should shake out into those that are practical and those that aren't, says analyst Roger Bedard of the Electric Power Research Institute, a think-tank based in Palo Alto, California. "It's still anybody's game."

Thorpe is more sceptical. "There are lots and lots of ideas out there and hundreds and hundreds of patents," he says. "Some of these actually defy the laws of physics, many of them will not be technically viable, even more of them would not be economically attractive - and we are left with very, very few designs that I think have a chance, on a 10- to 15-year timescale, of becoming economic."

Even now, the most promising designs can be washed under by the smallest technical glitch.
A short drive from Steenstrup's Wavestar rests a competing project: 237 tonnes of crimsonpainted steel and concrete dotted with barnacles. Curled up onshore, the Wave Dragon resembles a giant piece of playground equipment, its steep, curved walls sloping up to a large concrete bed with an opening at its centre. When operating, the Wave Dragon floats in open water; waves gush over its wall and into a hole, where they power a turbine.

Many see the machine as one of the industry's leading prospects. Installed in Nissum Bredning in 2003, the 20-kilowatt device ran for 20,000 hours, says Lars Christensen, a developer in Wave Dragon's Copenhagen office. But the machine has been ashore since early this year after a rusted screw put it out of commission. The screw, it turned out, should have been made of stain-

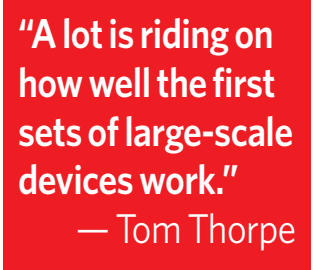
moored loosely to the ocean floor, allowing them to better absorb a pummelling. "The ocean is really going to beat these things up," says Hagerman. "They need to be out there for a few years to demonstrate that they can survive."

In 1988, a severe storm destroyed a 600kilowatt pilot plant made by Kvaerner Brug, a Norwegian firm. The shore-based machine - one of the few built in the 1980s - produced power for just three years, and the company later abandoned wave energy. Not to be deterred, Wave Dragon plans to install an even larger model next year in Wales, where the waves dwarf those in Denmark.

Although technical hurdles could torpedo any one machine, engineering alone is unlikely to sink the whole field, says Thorpe. He sees greater challenges in the less steel. And Finavera's Aqua Buoy was apparently sunk by a pump that failed to remove water once the device started leaking.

\section{Trial by error}

Such minor errors underscore the difficulty of engineering devices to withstand the demands of the open ocean. Waves come in all shapes and sizes, and most devices are designed to run on average ones. Yet to last years without regular maintenance, they must withstand swells twenty times more powerful. To counter such storms, many of the new machines are potential costs of developing and delivering wave energy in the face of competition from traditional and other renewable sources. "Technically it will work," he says. "Getting the cost down is a significant challenge, and I think some of them are going to be successful - but not that many."

The UK-based Carbon Trust has estimated that wave power costs between 25 and 91 US cents per kilowatt-hour. Investing some $£ 2.2$ billion (US $\$ 4.6$ billion) could bring the cost down to 12 cents per kilowatt-hour, it estimates, although that will depend on cost-cutting

\section{Energy from the sea}

Waves are just one way to extract power from the oceans; at least three other technologies attempt to harvest electricity from the sea.

Tidal power, captured from the tides as they rise and ebb, is a resource estimated at 91 gigawatts, according to a report from the UK consulting firm AEA.

In the United States, most of the tidal resource is in Alaska, far from populations and energy infrastructure. Other sites, such as San Francisco Bay in California, aren't ideal because of competition with shipping lanes. "Under the Golden Gate Bridge," says Roger Bedard of the Electric Power Research Institute in Palo Alto, California, "it ain't going to happen." Still, at least one firm has managed to make tidal energy work in a densely populated area.
Since 2006, Verdant Power has worked to extract about 1,000 kilowatt-hours per day from the tidal flows in New York City's East River, although the turbines are now under repair (pictured).

More projects are under way in Europe. France has kept its 240-megawatt La Rance tidalenergy plant in operation since the 1960s. New tidal technologies use turbines powered by beefed-up propellers that spin as the tides rise and fall. But in the French plant, the tides pump water behind a barrier. The 'dam' is then released to create power.
Such designs have not gained widespread use mainly because of environmental concerns.

The sea's largest cache of energy is thermal, with an estimated resource of 1.1 terawatts. The idea is to get electricity by tapping into the roughly $20^{\circ} \mathrm{C}$ temperature difference between the surface water in tropical waters and that pumped from depths of 1,000 metres or so. In the 1970s, the United States invested heavily in such thermal energy; several small plants generating up to 50 kilowatts were built in
Hawaii, although funding dried up in the mid-1990s. Lockheed Martin is now exploring the possibility of building new plants in conjunction with the US Navy.

Finally, the chemical difference between fresh water and sea water holds energy in the form of a salinity gradient that can create water pressure and run a turbine. The global salinity resource is estimated at 220 gigawatts, but the technology to tap this source has lagged behind the others. Statkraft, a Norwegian firm, has now opened a laboratory in Trondheim to look into it. The largest technical barrier seems to be the membrane that maintains a salt concentration between salt water and fresh, according to AEA. E.C. 
